\section{Reply to Commentary response by Wanigaratne, Mawani, 0'Campo, et al}

\author{
Meghan O'Neill (10, ${ }^{1,2}$ Emmalin Buajitti $\mathbb{B}^{1}{ }^{1,2}$ Peter Donnelly, ${ }^{3}$ \\ Kathy Kornas, ${ }^{2}$ Laura C Rosella (id ${ }^{2}$
}

We thank Wanigaratne and Mawani et al for taking the time to write this Commentary, ${ }^{1}$ which we have read with great interest. We agree that the framing and interpretation of findings about immigrant and refugee communities is of great importance and appreciate the opportunity to provide clarification. We would first like to acknowledge the valuable expertise of the authors as well as their strong relationships and vital advocacy work within communities.

The primary aim of our study was to provide descriptive epidemiology of homicide in Ontario. ${ }^{2}$ Very few population-level descriptive studies have been published characterising homicides, particularly regarding trends in homicide victimisation between and across population subgroups. Our study team includes epidemiologists, professional and academics who work at the intersection of public health and violence, experience with implementing violence prevention programmes in marginalised populations around the world and expertise in working with large linked health administrative data.

The linked health and administrative databases we used help fill the data gap with respect to understanding the victims of violence, including but not limited to refugee status. ${ }^{3}$ This aim is consistent with other descriptive database studies published about health and health system outcomes among immigrant and refugee populations in Ontario. ${ }^{411}$ The motivation for this study was to provide descriptive data that can be used by communities and researchers to better understand the distribution of health outcomes across populations. Our study found differences in risk of homicide across several social and economic indicators, including lower

\footnotetext{
${ }^{1}$ Institute for Clinical Evaluative Sciences, Toronto, Canada

${ }^{2}$ University of Toronto Dalla Lana School of Public Health, Toronto, Canada

${ }^{3}$ Public Health Ontario, Toronto, Canada
}

Correspondence to Laura C Rosella, University of Toronto, 155 College Street, Health Sciences Building 6th Floor, Toronto M5T 3M7, Canada:

laura.rosella@utoronto.ca socioeconomic status, urban centres and being a young male. Our interpretation of findings was informed by the descriptive aim of our paper and was intended to contextualise but not explain the results of our analysis.

We would like to emphasise an important point regarding the information that was available to the researchers. Specifically, these data do not contain any information on perpetrators of homicide, and our findings describe risk of homicide victimisation, or death by homicide, only. As emphasised in our paper, our study does not describe any information about perpetrators and should not be interpreted as such. Therefore, when we listed factors that may be more prevalent in immigrant communities, we were only referring to factors that may increase risk for victimisation and not perpetration.

As the authors point out, our results regarding the association between refugee status and homicide victimisation were not statistically significant and we were dealing with small numbers of homicides, with the two matters likely being related to each other. Ontario has relatively few homicides, and our small 'sample' of homicides was a population census of all homicide deaths during this time. Thus, we felt that our point estimates were meaningful, even if they did not rise to the level of statistical significance. $^{12}$ Moreover, it is unclear whether statistical significance should be the arbiter of public health significanceincluding the important community-based work mentioned by the authors-particularly in a descriptive study like ours. ${ }^{13}$ In accordance with concerns regarding statistical significance expressed in the field, readers should note the cautionary language used to discuss our findings. ${ }^{12} 14$

We agree with the authors that framing of the work is important and we were driven by commonly understood frames of understanding for the social determinants of health, ${ }^{15}{ }^{16}$ if implicitly so. Given our research context, we made several efforts to consider and reflect how individual risk is nested within broader social systems at interpersonal, community and societal levels, each of which uniquely reflect the greater political, economic and cultural contexts. It is for this reason that we mentioned many of the experiences faced by refugees in our discussion. The data to which we had access included one measure of context, area-level socioeconomic status, which we included in our analysisbut acknowledge this is extremely limited and does not capture the important prior mentioned points.

Indeed, we very much agree and would like to further emphasise that homicide victimisation is not under the control of the individual. The contextual information provided to interpret our findings have been reinforced by previous literature. For example, a recent scoping review emphasised the need to consider gender bias which often affects the health of women within immigrant communities, particularly with respect to experiencing interpersonal violence. ${ }^{17}$ In fact, previous research has used the same data sources as our study to examine the association between immigrant and refugee status and risk of postpartum suicide, homicide, assault and preterm birth, ${ }^{4-6} 18$ which are important indicators of violence victimisation.

The authors highlighted the important point that immigrant and refugees are at an increased risk of experiencing racism and this may have certainly contributed to differential patterns in findings. Unfortunately, linked health administrative data in Ontario do not capture information about race or ethnicity, which is a critical piece in furthering the understanding of these findings. Because those data were not available in these databases and consistent with our descriptive analysis, we did not discuss race or ethnicity in our interpretation of the findings. This is a gap and a limitation we certainly acknowledge with these types of studies.

We thank Wanigaratne and Mawani et al for drawing attention to communitybased participatory research, and we agree that this approach, led by experts in these methods, will add substantial value to the ongoing research. These methods engage individuals and communities who have been impacted by violence, which we strongly support. We anticipate that community engagement would generate meaningful insights into the contextual factors that may increase risk of homicide victimisation but are not captured by existing data sources available to health researchers and would guide research and policy priorities in a direct way. We understand and have stated that the data alone cannot provide a comprehensive picture of the social 
context of homicide victimisation and fully support further research in this area.

We also recognise the impact of social factors on risk of being a victim of violence, including access to education, economic status, linguistic capacity, and that immigrants are uniquely shaped by their experiences prior to arrival in Ontario. We recognise the importance of providing diverse social supports and resources (ie, adequate housing, employment and training opportunities, counselling and mental health services, access to translation services) and the importance of resettlement supports in improving all health outcomes in immigrant and refugee populations. We appreciate and support the suggestions made by the authors regarding broader prevention strategies, and acknowledge the important points raised, including prevention strategies targeted at all populations that address the structural factors that influence risk of violence. ${ }^{19}$

Our descriptive paper provides a starting point and raises important-and complexquestions about the distribution of risk for homicide victimisation in Ontario. We look forward to the research that Wanigaratne and Mawani et al will continue in this area using different methods and approaches to incorporate community-level input and context. We would also like to recognise the important work done by refugee advocacy groups, including the authors of this letter, and look forward to their leadership in the future use of these data.

Contributors MO prepared the initial drafts of the reply withadditional input from $E B, P D, K K, L R$. All authors reviewed thefinal version of the response. All authors contributed equally.

Funding The authors have not declared a specific grant for this research from any funding agency in the public, commercial or not-for-profit sectors.
Competing interests None declared.

Patient consent for publication Not required.

Provenance and peer review Commissioned; internally peer reviewed.

(C) Author(s) (or their employer(s)) 2020. No commercial re-use. See rights and permissions. Published by BMJ.

\section{Check for updates}

To cite O'Neill M, et al. J Epidemiol Community Health 2020;74:979-980.

\section{Sinked}

- http://dx.doi.org/10.1136/jech-2019-213249

J Epidemiol Community Health 2020;74:979-980. doi:10.1136/jech-2020-214792

\section{ORCID iDs}

Meghan O'Neill http://orcid.org/0000-0001-9551-0967 Emmalin Buajitti http://orcid.org/0000-0002-31947331

Laura C Rosella http://orcid.org/0000-0003-4867-869X

\section{REFERENCES}

1 Wanigaratne S, Mawani FN, O'Campo P, et al. Commentary in response to 'characterising the risk of homicide in a population-based cohort' (O'Neill et al, 2019). J Epidemiol Community Health 2020.

2 O'Neill M, Buajitti E, Donnelly PD, et al. Characterising risk of homicide in a population-based cohort. J Epidemiol Community Health Epub ahead of print 9 Dec 2019.

3 Adhia A, Bhatia A, Violence Against D-HE. Immigrant youth in Canada: why more research is needed. JAMA Network Open 2020;3:e201456-e56.

4 Wanigaratne S, Cole DC, Bassil K, et al. The influence of refugee status and secondary migration on preterm birth. J Epidemiol Community Health 2016;70:622-8.

5 Saunders NR, Guan J, Macpherson A, et al. Association of immigrant and refugee status with risk factors for exposure to violent assault among youths and young adults in Canada. JAMA Netw Open 2020;3:e200375-e75.

6 Vigod SN, Arora S, Urquia ML, et al. Postpartum self-inflicted injury, suicide, assault and homicide in relation to immigrant status in Ontario: a retrospective population-based cohort study. CMAJ Open 2019;7:E227-E35.

7 Anderson KK, Cheng J, Susser $E_{\text {, et al. Incidence }}$ of psychotic disorders among first-generation immigrants and refugees in Ontario. CMAJ 2015;187:E279-E86.

8 Khan S, Yao Z, Shah B. Gestational diabetes care and outcomes for refugee women: a population-based cohort study. Diabetic Med 2017;34:1608-14.

9 Durbin A, Jung JK, Chung $H$, et al. Prevalence of intellectual and developmental disabilities among first generation adult newcomers, and the health and health service use of this group: a retrospective cohort study. Plos One 2019;14:6.

10 Shen SC, Lofters A, Tinmouth J, et al. Predictors of non-adherence to colorectal cancer screening among immigrants to Ontario, Canada: a population-based study. Preventive Med 2018;111:180-9.

11 Lofters AK, Moineddin R, Hwang SW, et al. Predictors of low cervical cancer screening among immigrant women in Ontario, Canada. BMC Womens Health 2011;11:20.

12 Amrhein V, Greenland S, McShane B. Scientists rise up against statistical significance. Nature Publishing Group, 2019.

13 Amrhein V, Trafimow D, Greenland S. Inferential statistics as descriptive statistics: there is no replication crisis if we don't expect replication. Am Stat 2019;73:262-70.

14 Greenland S, Senn SJ, Rothman KJ, et al. Statistical tests, $P$ values, confidence intervals, and power: a guide to misinterpretations. Eur J Epidemiol 2016;31:337-50.

15 Acevedo-Garcia D, Sanchez-Vaznaugh EV, ViruellFuentes EA, et al. Integrating social epidemiology into immigrant health research: a cross-national framework. Soc Sci Med 2012;75:2060-8

16 Organization WH. A conceptual framework for action on the social determinants of health. 2010.

17 Januwalla $A$, Pulver $A$, Wanigaratne $S$, et al. Interventions to reduce adverse health outcomes resulting from manifestations of gender bias amongst immigrant populations: a scoping review. BMC Womens Health 2018;18:104-04.

18 Saunders NR, Lebenbaum M, Stukel TA, et al. Suicide and self-harm trends in recent immigrant youth in Ontario, 1996-2012: a population-based longitudinal cohort study. BMJ Open 2017;7:e014863-e63.

19 Donnelly PD, Ward CL. Oxford textbook of violence prevention: epidemiology, evidence, and policy. USA: Oxford University Press, 2015. 